\title{
A close encounter with ghost-writers: an initial exploration study on background, strategies and attitudes of independent essay providers
}

\author{
Shiva Sivasubramaniam * (1), Kalliopi Kostelidou and Sharavan Ramachandran
}

\footnotetext{
* Correspondence:

shiva.sivasubramaniam@ntu.ac.uk

School of Science and Technology, Nottingham Trent University, Clifton Lane, Nottingham NG11 8NS, UK
}

\begin{abstract}
Academic dishonesty presents in different forms, including fabrication of data, falsifying references, multiple submissions, collusion, and sabotage, with two forms haunting academia, namely plagiarism and contract cheating or ghost writing. These latter forms have received considerable attention and have been subjects for research. This interview-based study provides some further insight into the problem of ghost writing through presenting the attitudes, justifications and networking practices of some hired 'ghost-writers' from a developing country and discusses the depth of this emerging threat to the academic community.

Initially, through simple internet searches using specific keywords, an array of professional advertisements selling contract writing services were identified. Some of these promotional advertisements were found in Facebook ${ }^{\circledR}$ posts, and/or Twitter ${ }^{\circledast}$ feeds. The second part of this study presents a summary of findings from interviews of a group of ghost-writers including their background, attitude and justifications for setting up this new business. The study identifies several high calibre post-graduates who have come to understand the Western (European/North American/Australian) ways of scientific writing and have produced a network of 'consultancy' services. Although the birth of their business was ad-hoc, they have established a good network and are now able to share projects and practices. Many of them offer services to home and foreign students with varied levels of customer focus. Some of them are even using Turnitin $^{\odot}$ software to identify text matching issues. This study suggests that these paper mills have widely been subscribed to by students. The article finally discusses wider issues arising from these interviews and proposes some ways of tackling this new threat to academia.
\end{abstract}

Keywords: Plagiarism, Internationalisation, Social media, Contract cheating, Ghost-writers, Paper mills

\section{Introduction}

Academic dishonesty can present in a variety of forms, including data fabrication, falsifying references, multiple submissions, collusion and sabotage. Two common forms of academic dishonesty which haunt academia are plagiarism and ghost writing or contract cheating. The term 'contract cheating' was coined by Clarke and Lancaster, when they used IT-based tools to track bids by students trying to outsource computer work on the

(c) 2016 The Author(s). Open Access This article is distributed under the terms of the Creative Commons Attribution 4.0 International License (http://creativecommons.org/licenses/by/4.0/), which permits unrestricted use, distribution, and reproduction in any medium, provided you give appropriate credit to the original author(s) and the source, provide a link to the Creative Commons license, and indicate if changes were made. 
internet (Clarke and Lancaster 2006). In contrast 'ghost writing', has several distinct meanings, depending on the level of involvement of the ghost-writer (POGO 2011; Bosch and Ross 2012). Some examples, such as autobiographies that are mostly written collaboratively by a named author and ghost-writer, are considered ethically acceptable providing the use of the ghost-writer is properly acknowledged. In contrast, 'contract cheating' in which the student/academic is using/paying ghost-writers to complete parts of or entire projects without any inputs of their own, or proper acknowledgement is defined as academic dishonesty. Dedicated businesses such as essay mills/paper mills or writing services, as they are often presented, are being set up to serve these customers.

Since many Western (see methodology for definition) universities have incorporated text-matching software checks as a part of the submission process, plagiarism has been somewhat deterred, if not always detected (Sivasubramaniam 2013). However, there is less focus on addressing the issue of ghost writing or buying essays from paper mills (Molinari 2014). As Rothschild (2011) argued, although ghost writing is technically plagiarism under strict definition, many institutions fail to address it as a problem. Based on personal discussions with some 30 academics in the Bioscience field, approximately $60 \%$ believe that a professionally ghost written article can easily be identified either by text matching detection software, by its style or use of citation. They also think that essays from most paper mills are too expensive for undergraduates to buy, since they are only going to contribute a percentage to their final degree. The former belief is based on assumption that ghostwriters do not spend much time researching the subject and therefore may use internetbased articles, or may sell basically the same essay, or parts of it, more than once. However in reality, it is impossible to detect an article carefully ghost written by an expert just by using text matching software. The second assumption is based on the idea that ghostwriters are professional experts who would charge high fees that are unaffordable by most students. However, it is questionable whether all ghost-writers are professionals.

Due to internationalisation of education, availability of web resources coupled with the spread/penetration of social media and their broad use by the young generation have together invalidated these assumptions.

So what is the connection between internationalisation, social media and ghost writing? Many students with postgraduate qualifications from Western Universities are returning to their native countries to face a grim future as regards employment. Having studied internationalised curricula and established global links via social media, some of these students can and do start new ghost writing services. These services are easily accessible, economical, and above all, provide realistic essays that resemble an original student essay which may be precise, but include common student mistakes.

This article first captures the extent of internet presence of ghost writing advertisements and then investigates the attitudes and justifications of a group of hired 'ghostwriters' from a developing country, as well as their working and networking practices, to examine the depth of this emerging treat to the academic community.

\section{Methodology}

Terms used in this work

For the purposes of this work, terms used are defined as follows: 'ghost-writer' the person who authors essays, books, articles, theses which are credited to another person. For the present work, 'ghost writing' is used to describe the act of ghost writing, namely 
hiring a ghost-writer to author an academic assignment. Synonymous terms used in this paper are: contract-cheating, marketing of writing services, paper mills and essay mills. Although the actual definition of these terms may vary, the resulting phenomenon is the same, i.e. provision of an authored work, for a fee. 'Western' is used in the text to refer to Anglophone universities from Europe (any country), Northern America (USA and Canada), or Australia/New Zealand. 'Commercial Essay Providers' and 'Amateur Writers' are used according to their respective establishments. The former is used to depict a network of well-established writers;the latter to describe non-professional independent writers.

\section{Concept of this work - online search}

The idea of carrying out this exploratory study was initiated in 2013 after reading a Facebook $^{\odot}$ post (advertisement) about 'high quality help for writing assignments'. Following this, a Google ${ }^{\circ}$ (UK-Version 49.0.2623.112 m) search was immediately carried out using words linked to the term 'ghost-writers' such as 'ghost writing'; 'how to ghost write'; 'detecting ghost writing', to capture the extent of popularity/presence of these words within the online community. A similar search was performed in April 2016 using other popular terms such as 'contract cheating' and 'professional writing service'. In 2013, the authors looked into social media such as Facebook ${ }^{\odot}$, Twitter $^{\circ}$, and What's App to identify 25 posts/advertisements for 'academic writing services'. These writers were randomly selected and contacted through phone calls, when authors explained the purpose of the study. Out of the 25 , only ten agreed to participate so they were sent an invitation, with more details. All responders were given details of the purpose of this study, its mode of investigation and ethical aspects involved, including maintaining confidentiality. The study included interviews with the ten ghost-writers/organisations. Representing different subject areas but mainly Biosciences, they were all educated in Western countries and had since returned to their country of origin. Because these interviews were conducted in a different country from that of the author's institution, ethical issues were covered by conducting them under UNESCO's 'Norms of Journalistic Conduct' as described within the country in which these interviews were carried out. For reasons of confidentiality, this file cannot be presented, as it would expose the country where the interviewed ghost-writers were based. As almost all of the interviewees considered their work as a 'professional writing service' or 'project', the term 'ghost writing' was avoided in interviews. Interviews were held face-to-face with a duration of approximately fifteen minutes or by email. Comments and answers by the interviewees were recorded. These notes were subsequently re-read and key points selected to be reproduced in this text and commented upon. All interviews took place between March and to December 2013.

The purpose of these interviews was to assess (a) the individual background/circumstances for starting or joining this service (b) its popularity (c) its reliability/affordability and (d) whether they considered their service as academic dishonesty. Some examples of questions, taken from each category are given in the Appendix. While these questions were posed to the interviewees, specific answers were not always received and data presented only refer to the answers received.

Voluntary contributions of few ghost written articles were also collected to check their authenticity using the text matching software Turnitin ${ }^{\bullet}$ - Moodle Direct Version 2.2.1. 


\section{Results}

\section{Online searches}

General online searches were carried out to capture the numbers of hits on ghost writing in Google ${ }^{\oplus}$ to obtain an idea of the extent and popularity of this phenomenon. Searches were carried out in 2013 when this work started and repeated in 2016. Initially only the term ghost writing was used as a search keyword, while in the most recent search (2016) we also included 'contract cheating'. The terms used are shown in Table 1. As search keywords, phrases containing either neutral or positive connotations were included e.g. 'how to ghost write,' 'definition of contract cheating', or negative ones such as 'problem of ghost writing', 'detecting ghost writing', 'contract cheating in Higher Education'. The overall search data is summarised in Table 1.

As can be seen in Table 1, Google ${ }^{\bowtie}$ searches revealed that ghost writing is extensively publicised online under different terms, for instance ghost writing, writing services etc. Interestingly in 2013 when this study began and with the use of the term 'ghost writing', phrases with 'encouraging' connotations, such as 'how to ghost write' or 'ghost writing' achieved a high number of hits, while corresponding ones with deterring connotations, as 'detecting ghost writing' or 'problem with ghost writing' had fewer hits. The most recent search in April 2016, however, revealed a few interesting points. First, the phrase 'problem of ghost writing' has increased its number of hits by $458 \%$ (Table 1, row 2). Also the number of hits for 'ghost writing' has risen by an impressive $1499 \%$ (Table 1, row 1). This trend not only reflects the increasing penetration and spreading of ghost writing but also increased awareness of this service. Interestingly, all the other entries, such as definition of ghost writing, 'how to ghost write' 'ghost writing in higher education' and also 'detecting ghost writing' have been markedly reduced in number of hits $[-21 \%$ for 'how to detect ghost writing';-92 \% for 'how to ghost write']. We would like to believe that these observations could be due to a universal tendency to use 'contract cheating' instead of 'ghost-writer'.

A Google Scholar ${ }^{\oplus}$ search using the entire phrase 'contract cheating' which was performed on 15 April 2016 and excluded patents and citations, retrieved 197 articles. A large proportion of these were by Clarke and Lancaster. This was expected as these authors have presented pioneer work in this subject since 2006 and have since published several manuscripts (Clarke and Lancaster 2007, 2009, 2012). Simply changing the search term into 'ghost writing', but maintaining the exact search criteria retrieved 160

Table 1 Summary of Google ${ }^{\circledR}$ searches for phrases containing 'ghost-writer'

\begin{tabular}{llll}
\hline Search term & Hits 2013 & Hits in 2016 & Percent difference* $^{*}$ \\
\hline Ghost writing & 794,000 & $12,700,0000$ & $1499.2 \%$ \\
Problem of Ghost writing & 480,000 & $2,680,000$ & $458.3 \%$ \\
Definition of ghost writing & 878,000 & 540,000 & $-38.5 \%$ \\
Ghost writing in higher education & 469,000 & 367,000 & $-21.7 \%$ \\
How to ghost write & $55,672,000$ & $4,270,000$ & $-92.3 \%$ \\
Detecting ghost writing & 114,000 & 90,100 & $-21.0 \%$ \\
Contract cheating & $\mathrm{NA}^{\mathrm{a}}$ & $23,000,000$ & $\mathrm{NA}^{\mathrm{a}}$ \\
Definition of contract cheating & $\mathrm{NA}^{\mathrm{a}}$ & $6,460,000$ & $\mathrm{NA}^{\mathrm{a}}$
\end{tabular}

A positive/negative percentage denotes the increase/reduction in number of hits respectively ${ }^{a} N A$ Non-applicable

*Negative numbers show a percentage reduction 
entries, mostly linked with ghost writing in the medical sector and industry-sponsored ghost writing on clinical trials.

\section{Social media searches}

Social media searches have revealed several small to medium size advertisements, blogs and chatting strings concerning these 'writing services'. They were embedded as tweets, or Facebook ${ }^{\circledR}$ entries, which are linked to a home page. Some example screen shots are given in Fig. 1.

These advertisements are taken as screen-shots from social media and anonymised. Five of the anonymised advertisements are from ghost-writers 3, 4 and 5, 7 and 8, who were later interviewed.

Almost all of the examples in Fig. 1 are openly offering 'writing help' and appear to be addressing university students, both undergraduate and post-graduate. At least one writer has managed to post his advertisement on the common student Facebook ${ }^{\circ}$ pages of a university. It is also interesting to note some are assuring, or claiming, that essays written by them would have less than $6 \%$ Turnitin $^{\circ}$ similarity matches (white arrow in Fig. 1, top left advertisement). This shows that these advertisers are fully aware of the

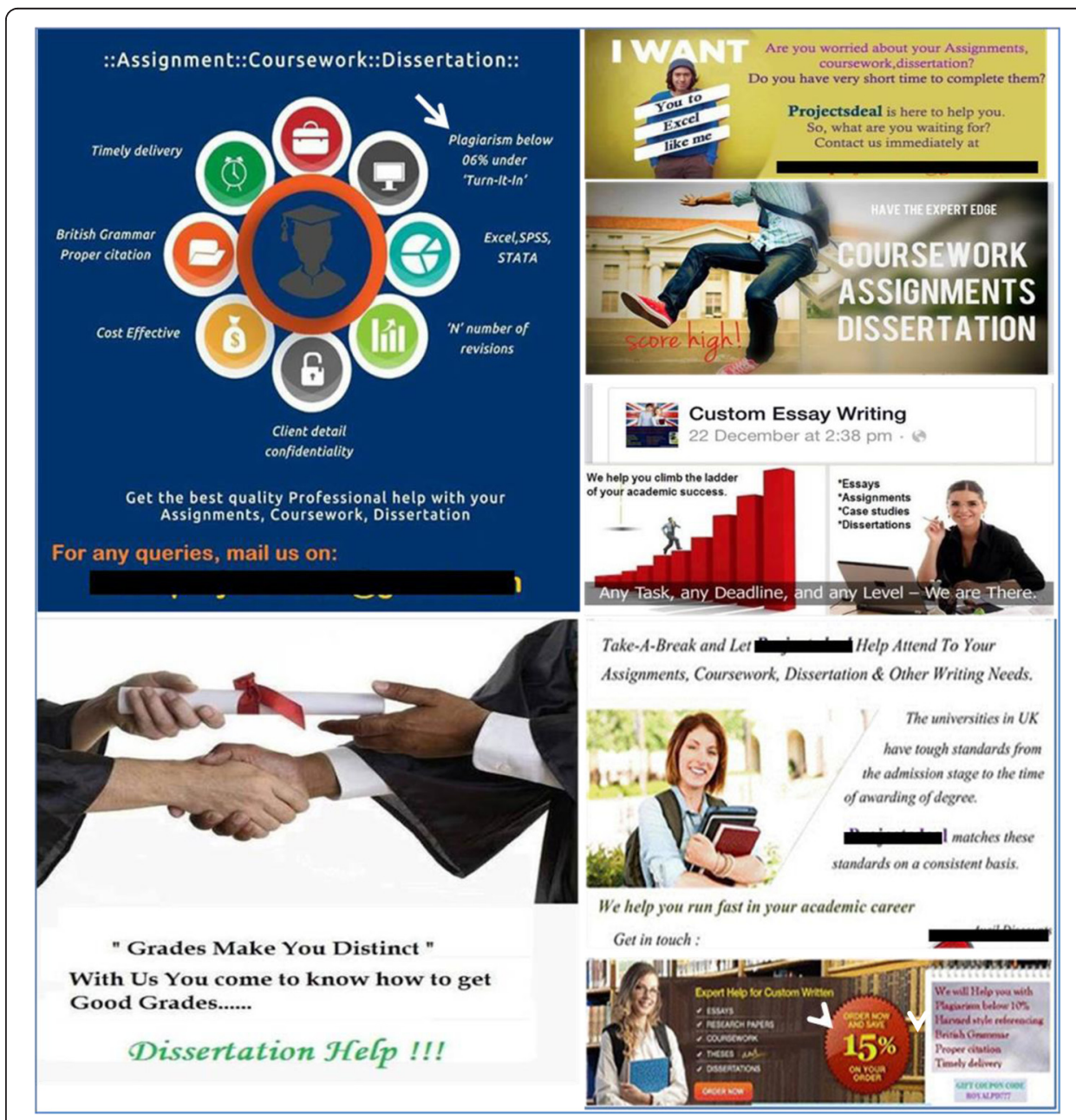

Fig. 1 Example advertisements from common social media websites 
use of text matching software in higher education (see section Qualitative data obtained from Interviews). Some offer discounts of up to $15 \%$, giving gift coupon codes (white arrow-head in Fig. 1, bottom right advertisement). Others offer help with thesis write ups, even at PhD level.

\section{Qualitative data obtained from Interviews}

A total of twenty five ghost-writers were approached and ten (40\%) consented to be interviewed following a confidentiality agreement that their personal identification, location, age and sex not be disclosed. Their educational profiles are shown in Table 2. Their qualifications are significant, with 90 \% having a post-graduate Master's degree and onea doctorate from Western Universities.

\section{Reasons for ghost writing}

Most of these services were started by students who returned to their home country after finishing post-graduate studies abroad. As a result of lack of employment in their field in their own country, some began as solos; others formed a consortium of friends from different fields of study. At least one interviewee claimed that $s /$ he never intended to start this as a business model but continued after realising his/her first two assignments were highly successful. All of those interviewed felt that there was a high demand for 'writers'. Commercial Essay Provider 1 held a doctorate in bioinformatics and had worked as a lecturer for a short period. During this time, s/he developed contacts with student communities. As for the incentive or reasons for starting this, s/he replied:

\section{'It was my own effort to start this service to our students studying overseas. I had utilized my acquired analytical and vocabulary skills to address the needs of our students.'}

Similar answers were obtained from Amateur Writers 7 and 8.

Amateur Writer 4 stated:

'One of my friends gives me projects to complete but I am planning to advertise through social networking sites.'

Table 2 Profiles of the interviewed ghost-writers

\begin{tabular}{|c|c|c|c|c|}
\hline Writer No & Contacted via & Master's degree & Doctorate degree & Expertise \\
\hline Commercial Essay Provider $1^{a}$ & Email & YES (MSC) & YES (Bioinformatics) & Bioscience \\
\hline Commercial Essay Provider $2^{\mathrm{a}}$ & Email & YES (MSC) & NO & Various \\
\hline Commercial Essay Provider $3^{\mathrm{a}}$ & Email & YES (MA) & NO & Various \\
\hline Amateur Writer $4^{\mathrm{b}}$ & Face to face & YES (MSC) & NO & Bioscience \\
\hline Commercial Essay Provider $5^{\text {a }}$ & Face to face & YES (MBA) & NO & Various \\
\hline Amateur Writer $6^{\mathrm{b}}$ & Face to face & YES (MSC) & NO & Various \\
\hline Amateur Writer $7^{\mathrm{b}}$ & Email & YES (MSC) & NO & Chemistry \\
\hline Amateur Writer $8^{\mathrm{b}}$ & Email & $\mathrm{NO}$ (BSc only) & NO & Engineering \\
\hline Commercial Essay Provider $9^{a}$ & Face to face & YES (ND) & NO & Various \\
\hline Commercial Essay Provider $10^{\mathrm{a}}$ & Face to face & YES (ND) & NO & Various \\
\hline
\end{tabular}

${ }^{a}$ Commercial Essay Provider = well established group of writing network

${ }^{\mathrm{b}}$ Amateur Writer $=$ non-professional independent writer

ND Not disclosed 
Although it appears these 'writers' started ad-hoc (mainly Commercial Essay Provider 1, 2, 9, and 10) they established a good network and were able to share projects and practices. Half of those interviewed advertise only in the social media as posts/tweets, not as advertisements. In contrast, others feel that advertising does not have an impact on their business and it is a waste of money.

Commercial Essay Provider 3 said:

'Advertising through main internet servers does not have any impact in our promotion; also Google ${ }^{\odot}$ have banned promotions for such report writing services.'

In their opinion (Commercial Provider 3), media can be used as a bridge for creating awareness and can also provide an opportunity to monitor market status. Eighty percent of the ghost-writers interviewed claimed they never used Google ${ }^{ø}$ for advertising. It should be noted that the initial Google ${ }^{\bullet}$ searches did reveal several ghost writing advertisements, many of which looked as if they came from professional Western organisations. There were also claims in Google ${ }^{\oplus}$ blogs by reformed ghost-writers that many Western paper mills outsourced their work to developing countries (Tamlyn, 2009). However none of the ghost-writers interviewed in this investigation seem to acquire 'projects' via this route. Their main forms of advertising are either through social media or personal contacts/networking. Considering claims from Tamlyn's (2009) and other similar blogs (Sydney media service ; Raven's Blog 2013) and comparing responses from this study, it is clear that there might be three groups of online based ghost writing services: (a) established Western country-based providers, (b) Western country-based providers who outsource their contracts and (c) those based and run by former students of Western education who are now based in their native, non-Western countries. From the replies received, participants of this study fall into the third group. As stated above, their personalised approach via Facebook $^{\odot}$ or through contacts might have improved their business. When interviewed many of them said that their 'service' is valued by students.

Amateur Writer 4 who started his service recently, stated:

'I mainly get projects through my references and contacts. Perhaps, my outstanding performances in various projects speak a lot, which I feel (is) better than commercial advertising'

However, Writer 4 did not deny that social media played a part in their 'popularity'. In fact, everyone agreed that the probability of students going to them via referrals and contacts by word of mouth/social media was higher than through advertising. The interviews also revealed that these writers are highly successful. One consortium of writers proudly claimed (Commercial Essay Provider 5):

'The frequency of our writing is constant and we get projects more frequently by any other means; so, our work and our service will fetch us further projects.'

Another writer (Amateur Writer 6) said:

'It depends upon the needs of the students and university. As I am handling the services to all degree students, irrespective of their level of study, it will be busy all 
year around. For international dissertation services, it will be very busy during the months of June and January.'

Due to this high demand, this writer is now recruiting and training $\mathrm{MSc} / \mathrm{PhD}$ holders from his own country. Seven writers admitted they have constant demand from both overseas and home students, the former being defined as those studying in overseas countries. As for expertise in a given subject, they share projects by networking, to ensure the is handled by an expert in subject's essay. For example, if a bioscience project is acquired by a provider with social science expertise, they would refer this on to an individual with bioscience specialism and vice versa.

\section{Reliability}

With respect to the reliability of their service, all interviewees had a clear understanding of academic writing and plagiarism avoidance. In fact some of them even use text matching detection software to reduce the percentage matches as they perfect their essays. An example email from a senior writer to their apprentice (Commercial Provider 3), highlighting the text matching issue with instructions to rephrase the essay and screen shots of a Turnitin ${ }^{\odot}$ report, is given in Fig. 2 .

An example email correspondence between writers within Commercial Essay Provider 3. Personal identifiers such as names, email addresses are removed as requested by the interviewee.

After showing this example, the provider (Commercial Essay Provider 3) quoted:

'We train them (the apprentice) to meet the international standards and requirements. By doing this, we can deliver plagiarism-free services to our international clients and customers.'

The same provider admitted that they clearly advise students how to address academic misconduct investigations. They are clever enough to use the student's (customer) name

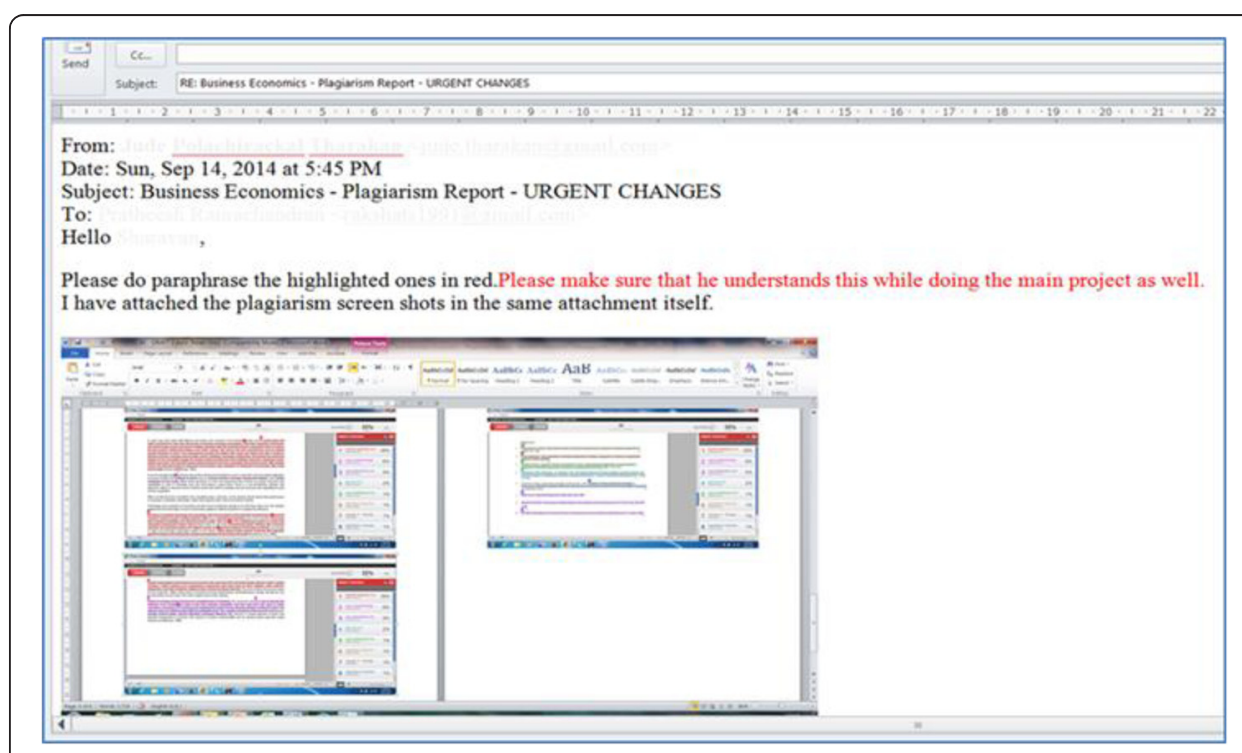

Fig. 2 Example communication between ghost-writers regarding a Turnitinœ report 
and their respective university registration numbers for $\operatorname{Turnitin}^{\odot}$ checks, so if detected, the student can claim they had checked the assignment for accuracy before submission.

Considering the seriousness of the claim that some ghost-writers are using Turnitin ${ }^{\circ}$ to reduce the percentage of text matches, the authors requested some of their (ghostwriters') past 'projects' to validate this claim. All but one, including those who claimed to be using Turnitin ${ }^{\circ}$, refused to provide any essays. The single ghost-writer who agreed was Commercial Essay Provider number 2, who provided four pieces of his/her work, two each for in-country customers and for students in Western universities. These four essays were checked for authenticity using Turnitin (Moodle Direct version 2.2.1) and the percentage matches are highlighted in Fig. 3. The right hand panels, which have a high similarity index with other published sources, were apparently written for in-country customers. In contrast, the left hand panels with low similarity index were produced for students studying in Western countries.

Screen shots of Turnitin ${ }^{\circ}$ reports on articles that are claimed to be written for international (panels A and C) and in-country students (panels B and D) are given on the left and right respectively. The percentage matches are 5 and $8 \%$ for panels $\mathrm{A}$ and $\mathrm{C}$ respectively and 75 and $54 \%$ for panels B and D respectively. Percentages are circled on the top right part of each panel.

It is interesting to note that within the country where this study was conducted, the number of Universities/Higher education institutions which actually make use of any form of text matching services or programmes to check for academic dishonesty is below $1 \%$ (the data was arbitrarily collected from 100 university websites in that country). A potentially low level of detection may have been realised by these writers, who may be offering widely copied material to in-country students. Although the sample size is too limited to give a meaningful conclusion, this data points to a customerfocussed service being offered by these ghost-writers. They may be trying to offer

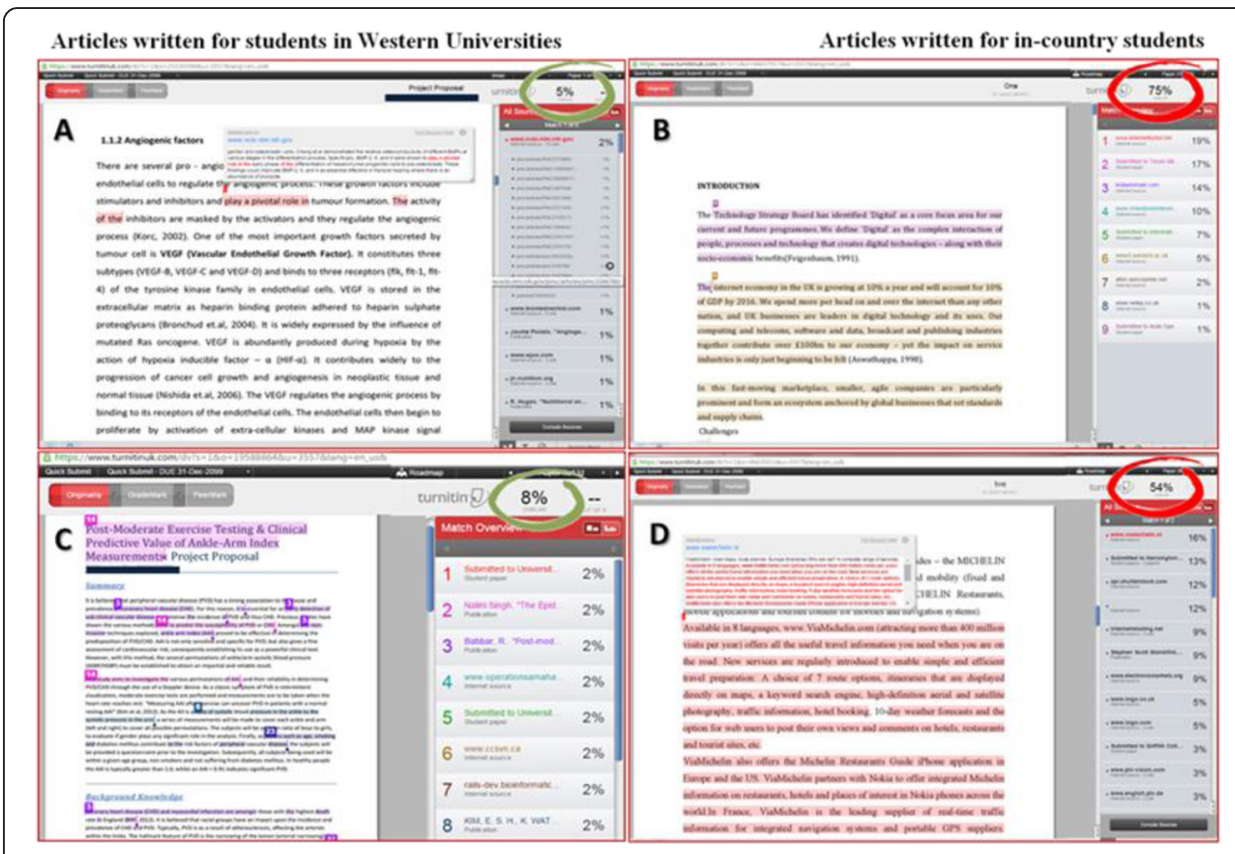

Fig. 3 Percentages matches of example articles supplied by the ghost-writers 
customised essays to students in Western countries where academic honesty is properly checked, whilst for their in-country customers producing essays that just address learning outcomes by copying, or 'patch-working'. Patch working is mixing and matching sections of other essays into a new one, rather than carefully reading and then paraphrasing content of the sources to create an original piece of work. It is interesting to note, that the author (Commercial Essay Provider 2) who supplied these essays, when confronted with this evidence denied the accusation that ghost-writers may be offering a two-tier customer service and claimed it was merely coincidental. Since this investigation only focussed on ghost-writing practices, their popularity and justifications, investigating this suspected two-tier service which is based on minimal evidence is beyond the scope of this study.

When prompted with the question about the morality of performing this service, the writers' argument was that the process of 'writing' usually involves the customer (student). They maintained their service is merely carried out in the form of collaboration with the customer, with whom they have a constant dialogue, making the student read their drafts and comments so that understand the essay and fulfil its learning outcomes. In other words they are claiming their role is as 'editors' rather than 'writers'. The following excerpt given by one of the ghost writing consortia (Commercial Essay Provider 5) summarises the attitude of these writers and clearly shows they know students' weaknesses:

\section{'Although the students from this (anonymised) country are highly focussed on} knowledge, they lag far behind when it comes to execution. This will mask their career growth. The main reason is that, they are not taught the importance of writing at preliminary levels. They are not aware of plagiarism. This is mainly due to the design of our (anonymised) educational system. Consequently, their research is not recognised in the international platform. We (the writers) are simply helping them to get recognised.'

Similar attitudes were observed in the answers of Commercial Providers 9 and 10. The writers understood the differences in expectations between Western and nonWestern assessments and use these differences to enhance their business. They are committed to their customers, promise to write better essays, and avoid plagiarism. One writer (Commercial Essay Provider 2) even accused the university system and its assessment practices by quoting:

'The lack of support from the university tutors with their (students) course work is the main reason for students to seek the assistance from us.'

\section{Affordability}

The authors of this manuscript have found that these writing services are substantially cheaper than paper mills located in Europe, US or Australia, especially for an under/ post-graduate who could afford to pay international tuition fees of the UK or USA. The charging practices differ from writer to writer. One (Commercial Essay Provider 3) claimed s/he charged the equivalent of 3 to $5 \mathrm{UK}$ pence per word with a minimum charge of $£ 100$. This is important evidence that contradicts the common academic belief that 'students cannot afford to buy an essay from an essay-mill'. The charges of the 
interviewed ghost-writers depend on the complexity of the project, from $£ 150$ for an undergraduate-level assignment to $£ 1000$ for a $\mathrm{PhD}$ thesis. Although some claimed they even wrote $\mathrm{PhD}$ theses, the authors were unable to gather any evidence for this.

\section{Summary of findings and concluding remarks}

Unlike plagiarism, there are no statistical data showing the extent of ghost writing amongst academics and students. This is justified by the difficulty in properly detecting these practices and possibly a general academic belief that ghost writing is not prevalent amongst university students. There is considerable published work on the subject of ghost writing/contract cheating (Clarke and Lancaster 2006, 2012) but our work first aimed to explore the online 'presence' of ghost-writers and secondly to capture their styles and attitudes towards their business, as well as shedding some light on their operative ways and networking practices.

To the best of our knowledge, this is the first work aiming to present collective opinions of a group of ghost-writers in an academic journal rather than a newspaper or blog. In this transformed world of communication, social networking plays a major part in discussing course-related matters amongst students of higher education (Roblyer et al. 2010; Connell 2009). Essay mills businesses have noticed the potential of these websites as an advertising platform (Todi 2008). The phenomenon of students using social networking sites to obtain educational support has already been described (Peluchette and Karl 2008; Roblyer et al. 2010), and the ghost-writers capitalize on this. They not only specifically yet discretely target large customer groups, but also twist its use to avoid creating a media outcry. Therefore, they endorse the strategy of posting for their 'availability' as a simple entry on the web, rather than tagging it as a proper advertisement. From our study, approximately $80 \%$ realised that their services may not be legal and could be blocked by the service providers.

Unemployment, particularly for specialised graduates seems to serve as the incentive for these people to starting such ventures, clearly indicating that a coveted international education may not currently be suitable for their country of origin at least for the present time. As Teichler (2004) stated, internationalisation of education without addressing core competency requirements of a global market results in unemployment. The fact that these ghost-writers are relatively recent graduates $(80 \%$ of them graduated within the last 5 years) clearly proves Teichler's point.

Another consequence of recent graduation is that these contract essay providers are accustomed to marking criteria, learning objectives and outcomes, and the overall styles required for assignments. In terms of originality, there are signs of a 'two-tier' service. One service is tailored to students in Western universities and includes the use of Turnitin $^{\odot}$ or similar programmes to detect/correct potential text matching issues. The second service is designed for in-country students and lacks any provision for plagiarism checks, as home universities lag behind in use of text matching software.

Regarding the question of ethics in academic writing, the writers' arguments were somewhat varied. By showing evidence, some (at least 2) tried to prove customer involvement throughout the project and therefore argued it is not unethical or immoral. The rest justified their service as similar to English Language Editing (ELE) services offered by many journals. One of the ghost-writers (Amateur Writer 6) even pointed out 
that it has been a common practice by Western academics to hire grant writers, and questioned how their service is dissimilar to this. Quoting Fugh Berman's (2005) manuscript about pharmaceutical industries using ghost written articles supporting the efficacy of new drug (before its release onto the market, (Commercial Provider 5) defended argument that ghost writing is a common and acceptable practice. They also questioned the authors 'why you (the authors) are only keen to investigate these practices in my country, instead of investigating the corporate ghost-writers of the West?

These findings may come as no surprise, but indicate that these interviewees have a clear understanding of their work. They know how to justify their existence as well as sustain and grow their business. As prices become affordable and business is growing, this new generation of ghost-writers is going to be a major challenge for the internationalised higher education system. Therefore it is necessary for institutions to focus and redesign their assessment strategies to remove the chances of ghost writing. A holistic approach, where the strategy of assessment by means of a written assignment as a 'measure of learning' is shifted to an approach that evaluate the 'learning process' through constant student engagement and input. Different levels of organisation are required from all involved stakeholders, including the students and the Government (Clarke and Lancaster 2007, 2009). Academic tutors need to tailor their assessment methods so that the process, as well as the outcome are assessed. It is also possible to have a test linked to an assignment, for example testing an element of the product, or to introduce team work activities. The latter was successfully introduced by the first author in his own institution. Administrative and IT staff can also be involved to perform regular checks on student fora, University websites and discussion pages.

University management needs to put in place a clear code of conduct and policies to deal with all the aspects of ghost writing, from detection to penalties to the involved student. Policy making can also be requested at Government level, which could result in cancelling the VISA of an overseas student who is proven culpable.

Obviously, dealing with contract cheating is not easy, especially in today's large departments and classes, but with the introduction of an array of measures and fostering of an altered perspective by students, ghost writing could be, at least to some extent, deterred.

\section{Appendix - some example questions asked during the interview}

\section{A. The Background (reasons for starting/joining)}

1. What was the main reason for starting this service?

2. Were you confident that you had the experience and/or expertise to start this project?

3. When you started this project how many others were involved?

\section{B. Popularity and accessibility}

4. How many projects per month do you usually undertake?

5. How do you advertise? (Whether you advertise? or do students contact you?)

6. How do you network? Do you share expertise? If so, how do you allocate/share projects? Are staff well trained to meet the International Standards? 


\section{Reliability and affordability}

7. What is your price range? And why do you think it is appropriate?

8. Who decides on price? You or the customer?

9. Do you think your price range is affordable by home/international students?

\section{Views on academic dishonesty and plagiarism}

\section{Do you know about academic dishonesty? What is your view regarding plagiarism?}

11. Do you think that your services contravene the code of practice in academic writing? If not, why?

12. Do you take steps to avoid plagiarism in your projects? If so, how?

Competing interests

The authors declare that they have no competing interests.

\section{Authors' contributions}

All authors contributed extensively to the work presented in this manuscript. SDS designed the research plan, organised the study and assisted in the analysis. SR carried out the survey and interviews; he also analysed the data and drafted the manuscript. KK has carried out the online based searches, addressed the issues pointed out by the reviewers and made the final draft. All authors read and approved the final manuscript.

\section{Authors' information}

Shiva Sivasubramaniam (SDS) is principal lecturer and Subject lead for Pharmacology. He has been an active researcher in developing novel approaches in teaching biomedical sciences. His pedagogic research interests include (a) internationalisation; (b) Student centred teaching, (c) peer-assisted learning and (b) plagiarism deterrence. Working closely with the Higher Education Academy (HEA) and Plagiarism Advisory Services (PAS), he has addressed student education by enhancing academic writing and graduate attributes. This has resulted in several publications in HEA and PAS conferences. He has also been involved in developing several post-graduate courses to suit the needs of international students without affecting the experience of home/EU students. In addition he has developed innovative teaching techniques to educate under- and post-graduate students and plagiarism deterrence.

Kalliopi Kostelidou (KK) is a lecturer/sabbatical assistant for the corresponding author.

Professor of Biochemistry, Department of Life and Health Sciences, School of Sciences. Her research interests include microbiology and pedagogic development. She is currently working to develop distance learning modules at postgraduate level. She is also involved in corresponding author's current research to develop methodologies to enhance student involvement.

Sharavan Ramachandran (SR) holds an MSc - Research degree in Bimolecular sciences from the Nottingham Trent University. He worked as a research assistant to SDS during this study. He is currently pursuing a PhD degree in molecular bioscience.

\section{Acknowledgements}

The authors would like to thank Dr Christopher Terrell-Nield, Nottingham Trent University for his editorial help and constructive criticisms throughout this study. The authors also wish to thank the editor and anonymous reviewers for their helpful feedback on this manuscript.

\section{Funding}

The study was internally funded by the Nottingham Trent University.

\section{Disclaimer statement}

A part of this study was presented in the 'Plagiarism across Europe and beyond 2015' conference at Mendel University in Brno, Czech Republic June 10th-12th 2015. Therefore some findings were published as a proceeding manuscript from this conference.

Received: 7 January 2016 Accepted: 16 June 2016

Published online: 01 July 2016

\section{References}

Bosch X, Ross JS (2012) Ghost writing: research misconduct, plagiarism or fool's gold. Am J Med 125(4):324-326

Clarke R, Lancaster T (2006) Eliminating the Successor to Plagiarism? Identifying the usage of contract cheating sites, in Proceedings of 2nd International Plagiarism Conference, Gateshead, United Kingdom, June 19-21, 2006

Clarke R, Lancaster T (2007) The Establishing a Systematic Six-Stage Process for Detecting Contract Cheating. Accessed 02 Apr 2016 
Clarke R, Lancaster T (2009) Contract Cheating in UK Higher Education: promoting a proactive approach (slides). Accessed 30 Mar 2016

Clarke R, Lancaster T (2012) Dealing with contract cheating: a question of attribution (PDF). Accessed 03 Apr 2016

Connell S (2009) Academic libraries, Facebook and MySpace, and student outreach: a survey of student opinion. Libr Acad $9(1): 25-36$

Fugh-Berman A (2005) The corporate Co-author. J Gen Intern Med 220(6):546-548. doi:10.1111/j.1525-1497.2005.05857.x

Molinari J (2014) Academic ghost writing: to what extent is it haunting higher education? The Guardian Thursday 3 April 2014. http://www.theguardian.com/higher-education-network/blog/2014/apr/03/academic-proofreadingwrite-essays-universities-students-ethics. Accessed 14 Apr 2016

Peluchette J, Karl K (2008) Social networking profiles: an examination of student attitudes regarding use and appropriateness of content. Cyberpsychol Behav 11(1):95-97

POGO - The Project on Government Oversight (2011). 'Frequently Asked Questions About Medical Ghost writing.' August 10th, 201 http://www.pogo.org/pogo-files/alerts/public-health/ph-iis-20110620. html\#what\%20is\%20corporate-funded\%20medical\%20ghostwriting? Accessed 09 Sept 2015

Raven's Blog (2013) http://blog.raventools.com/truth-about-ghostwriting/. Accessed 10 Sept 2015

Roblyer MD, McDaniel M, Webb M, Herman J, Witty JV (2010) Findings on Facebook in higher education: a comparison of college faculty and student uses and perceptions of social networking sites. Internet High Educ 13:134-140

Rothschild D (2011) Can Ghost writing Be Considered Plagiarism? Posted by David on Aug 17, 2011. http://www.ithenticate.com/plagiarism-detection-blog/bid/64034/Can-Ghostwriting-Be-ConsideredPlagiarism\#.VMkPr2isVPU. Accessed 2 Feb 2014

Sivasubramaniam, SD (2013) Electronic plagiarism detection software as self-teaching tool for plagiarism avoidance in Bioscience undergraduates. Conference Proceedings (Full Paper) Plagiarism across Europe and Beyond. Brno, Czech Republic June $12-13,2013 ; 149-158$

Sydney media service 1 - http://www.sydneymediaservices.com/10thingsyoumustknowabouthiringaghostwriter.html. Accessed 09 Sept 2015

Tamlyn S (2009) 11 Things Your Ghostwriter Doesn't Want You to Know. https://samtamlyn.wordpress.com/articles/ ghostwriter-doesnt-want-you-to-know/. Accessed 09 Sept 2015

Teichler U (2004) The changing debate on internationalisation of higher education. High Educ 48(5-26):2004 http://www.theguardian.com/higher-education-network/blog/2014/apr/03/academic-proofreading-write-essaysuniversities-students-ethics. Accessed 09 Sept 2015

Todi M (2008) Advertising on Social Networking Websites Wharton Research Scholars Journal Wharton School, University of Pennsylvania Scholarly Columns. http://repository.upenn.edu/wharton_research_scholars/52. Accessed 09 Sept 2015

\section{Submit your manuscript to a SpringerOpen ${ }^{\circ}$} journal and benefit from:

- Convenient online submission

- Rigorous peer review

- Immediate publication on acceptance

- Open access: articles freely available online

- High visibility within the field

- Retaining the copyright to your article 